\title{
EFFECT OF DIFFERENT TYPES OF EMITTERS AND IRRIGATION INTERVALS ON THE PRODUCTIVITY AND QUALITY OF SQUASH UNDER THE NILE DELTA CONDITIONS
}

\author{
A. A. Derbala' ${ }^{1}$ D. H. Elwan' ${ }^{2}$ and M. M. Amer ${ }^{3 \&^{*}}$
}

1. Prof., Ag. Eng. Dept., Fac. of Ag., Tanta U., Egypt.

2. Grad. Stud., Ag. Eng. Dept. Fac. of Ag., Tanta U., Egypt.

3. Assist. Prof., Ag. Eng. Dept., Fac. of Ag., Tanta U., Egypt.

*E-mail: mai.amer@agr.tanta.edu.eg

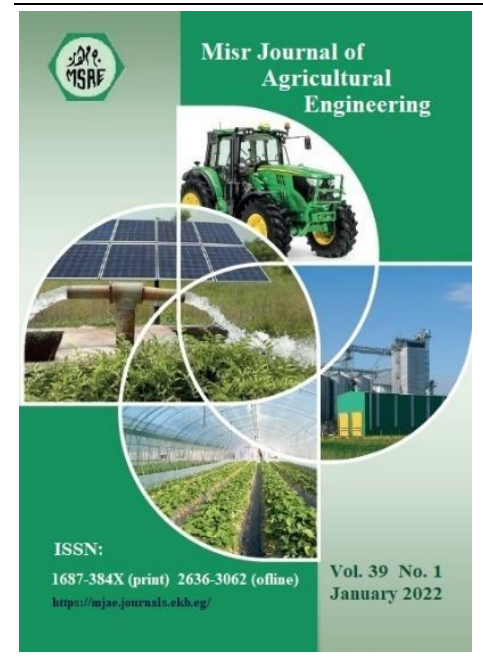

(ㄱ Misr J. Ag. Eng. (MJAE)
Keywords:

Drip irrigation; Emitter types; Irrigation intervals; Squash yield.

\section{ABSTRACT}

Drip irrigation considered as one of modern irrigation systems which used to reduce water losses and increase water use efficiency. The present work was conducted in the experimental farm of Faculty of Agriculture, Tanta University, during summer 2019. The work amid to study the response of squash to three different irrigation intervals "irrigation day after day; irrigation every three days and irrigation every five days" using $D_{5000}$, $P C_{N D}$ and $P_{2}$ emitters. The coefficient of variation " $C . V^{\prime \prime}$, emission uniformity "EU", statistical uniformity coefficient "Us" and Christiansen uniformity "CU" were calculated for all tested emitters. The results revealed that a significant effect of the irrigation intervals on the flow rate of all emitters under study. $D_{5000}$ showed the highest $C . V$ followed by $P C_{N D}$ type. The largest $C . V$ was shown in D5000 under irrigation every 5 days while the lowest one was presented in $P_{2} C_{2}$ under irrigation day after day. $E U, C U$ and $U s$ values for the tested emitters were larger than 90\%. $\mathrm{PC}_{2}$ had the highest value of EU, CU and Us followed by $P C_{N D}$. Emission uniformity, $C U$ and $U s$ negatively associated with irrigation intervals. Squash plants under $\mathrm{PC}_{2}$ emitter gave the highest fruit yield and fruit quality. The results revealed that a significant decrease in fruit yield and most related traits with the increase of irrigation intervals. Irrigated squash plants every three days resulted in high significant increase in fruit yield and fruit quality. Irrigated squash plants every three days using $\mathrm{PC}_{2}$ was recommended to increase the yield under the Nile Delta conditions.

\section{INTRODUCTION}

B ecause rainfall is insufficient during the year-long growing season, most Egyptian croplands must be irrigated. The increased demand for water, as well as its high cost, necessitates efficient water management. Irrigation practices are those that make the most efficient use of water. For crop cultivation, irrigation water is used. The method of irrigation is determined by the climate, soil, weather, irrigation system, and crop to be used information to use an irrigation system 
to schedule water. Irrigation methods vary from surface flood irrigation to drip and sprinkler irrigation, depending on the economic situation of the countries as well as the availability and quality of water resources. Most of the developed world countries have made a shift from traditional irrigation to modern irrigation methods such as drip or sprinkler irrigation. Many studies have confirmed the superiority of modern irrigation methods over traditional irrigation in many matters. For example, drip irrigation includes many features include increased yield, improved product quality, and reduced infection of leaf diseases (Locascio, 2005). Other advantages over classic irrigation include higher efficiency in water use and uniformity of application that is not affected by winds and causes less soil peeling. Also, drip irrigation need less energy and labor required. In addition, the use of fertilization through drip systems enables precise application and timing of fertilizers, resulting in enhance fertilizers use efficiency. On the other hand, drip irrigation can be used with success in both saline soils and saline water (Hanson et al., 2009). Finally, drip irrigation increases productivity and product quality. The shift to dripping is called the largest strategic improvement in water use efficiency and energy savings over the past three decades (National Research Council, 2010). Sarker et al., (2019) indicated that drip irrigation can improve uniformity in water distribution in root zone, water use efficiency, and crop productivity in both saline and non-saline lands. However, the currently available drip irrigation systems have limitations especially in the design and field performance of emitters. The emitters are considered one of the most important components of the system responsible for water distribution and uniformity in the root zone. Therefore, the process of choosing the appropriate emitters is very important, as many types of emitters are spread, including pressure equivalents and traditional ones. It is necessary to choose the emitters that show an acceptable performance (Ravina et al., 1997). The selection of good and timely emitters is the first step for drip irrigation method design, as well as, the similarity of the water application from drip irrigation method is reflected by both water pressure distribution in pipes network and properties of hydraulic of emitters (Abdelsalam, 2016).

The select of suitable emitter is very diffcult because there are many parameters effect on the emitter characteristics such as the crop, the soil and the topography; almost the respective choice regarding with high performance of the hydraulic system (Phocaides, 2000). Variation in the rate of flow coefficient of the emitter determine the clogging process, which is major caused by the kind of the water applied in irrigation, because of the trouble does not impact every emitter evenly (Ribeiro and Coelho 2010). Al-Mefleh et al., (2015) evaluated the performance of five types of emitters. They found insignificant difference between all tested emitter on C.V, EU, and CU under the different rates of pressure and clogging. Elamin et al., (2017) evaluated the hydraulic performance of drip irrigation system and they indicated that turbo emitter using one bar revealed a significant differences in increasing CU and EU.

In drip irrigation system, the similarity of water enforcement from the emitters on lateral lines length depends on emitters design, operating pressure, friction losses, the industrialization difference of emitter and emitter's tendency to clog. The uniformity of water is related to the pressure variation along the lateral line (Sinobas and Rodriguez, 2012). Sarker, et al., (2019) measured the emitter discharge rate for the variable operating heads of $1.5,2$, and $2.5 \mathrm{~m}$ with zero $\%$, one $\%$, and $1.5 \%$ slopes. Their results revealed that increase of irrigation intervals leads to decrease in 
all emitter performances. Also, Lui and Huang (2009) reported that the emitter performance characteristics are affected by water quality, emitter type, and time of operation.

The present work aimed to study the response of squash to three different irrigation intervals "irrigation day after day; irrigation every three days and irrigation every five days" using $\mathrm{D}_{5000}$, $\mathrm{PC}_{\mathrm{ND}}$ and $\mathrm{PC}_{2}$ emitters.

\section{MATERIALS AND METHODS}

The present work was conducted in the experimental farm of Faculty of Agriculture, Tanta University, during summer 2019 to evaluating the efficiency of three types of emitters i.e. $\mathrm{D}_{5000}$, $\mathrm{PC}_{\mathrm{ND}}$ and $\mathrm{PC}_{2}$ under three different irrigation intervals i.e. irrigation day after day, irrigation every three days and irrigation every five days in improving the drip irrigation efficiency and its effect on the growth, yield, and fruit quality of squash (Cucurbita pepo L.). Some physical and chemical properties of the experimental site are presented in Table (1).

Table (1): Some physical and chemical properties of the experimental site

\begin{tabular}{|c|c|c|c|c|c|c|}
\hline Properties & Clay, \% & Silt, \% & Sand, \% & Texture & pH & EC, dS/m \\
\hline $\begin{array}{c}\text { Season, } \\
2019\end{array}$ & 56.63 & 33.92 & 9.45 & Clay & 7.52 & 1.92 \\
\hline
\end{tabular}

The field experimental site was prepared and planned in split plot design with three replicates. The emitter types mentioned above were allocated in the main plots while the-irrigation intervals mentioned above were randomly distributed in sub plots.

\section{-Source and quality of irrigation water}

Fresh water was used to test the performance characteristics of different emitters and it's EC was $10.40 \mathrm{dS} / \mathrm{m}$ and $\mathrm{pH}$ was 7.78 .

\section{-The coefficient of variation}

The coefficient of variation "C.V" is a measure of the variability of discharge of a random sample of a given make, model, and size of the emitter. The classification of "C.V" values according to American Society of Agricultural Engineers "ASAE" Standards are shown in Table (2).

Table (2): American society of agricultural engineers "ASAE" classification of manufacturer's coefficient of variation

\begin{tabular}{|c|c|c|c|c|c|}
\hline $\mathbf{C . V}(\boldsymbol{\%})$ & $<\mathbf{5}$ & $\mathbf{5 - 7}$ & $\mathbf{7 - 1 1}$ & $\mathbf{1 1 - 1 5}$ & $>\mathbf{1 5}$ \\
\hline Classification & Excellent & Moderate & Marginal & Poor & Unacceptable \\
\hline
\end{tabular}

On the other hand, the coefficient of variation can be calculated according to (ASAE. 1998) as follows:

$$
\mathrm{C} . \mathrm{V}=\frac{s d}{q}
$$

Where:

$\mathrm{C} . \mathrm{V}=$ the coefficient of variation of emitter flow in $\%$,

$\mathrm{S}_{\mathrm{d}}=$ the standard deviation of emitter flow rates at reference pressure head in $\mathrm{L} / \mathrm{h}$, and

$q=$ the mean emitter flow rate in the sample at that reference pressure head in $\mathrm{L} / \mathrm{h}$. 


\section{-Christiansen's uniformity coefficient}

Christiansen's uniformity coefficient "CU" is calculated using Christiansen formula (ASAE, 1998) as follows:

$$
\mathrm{CU}=100 \%\left[1-\frac{\text { Average Deviation from the Average Depth of Application }}{\text { Overall Average Depth of Application }}\right]
$$

\section{-Flow variation}

The flow variation "quar" was calculated using the following Equation:

$$
q_{v a r}=\frac{\left(q_{\max }-q_{\min }\right)}{q_{\max }} \times 100
$$

Where:

$\mathrm{q}_{\mathrm{var}}=$ the variation of emitter flow in $\%$,

$\mathrm{q}_{\max }=$ the maximum of emitter flow rate in $\mathrm{L} / \mathrm{h}$ and

$\mathrm{q}_{\min }=$ the minimum of emitter flow rate in $\mathrm{L} / \mathrm{h}$.

\section{-Emission uniformity}

Emission uniformity "EU" is one of the most frequently used in design criteria for the drip irrigation systems. It is one of the indices for the evaluation of the drip irrigation systems. The "EU" is used primarily to describe the predicted emitter flow variation along a lateral line. To estimate design uniformity in terms of "C.V" and pressure variations, the following equation was used (ASAE, 2014).

$$
\mathrm{EU}=\frac{100[1-127 \mathrm{CV}]}{\sqrt{n}}
$$

Where:

$\mathrm{EU}=$ the design emission uniformity in \%, and

$\mathrm{n}=$ the number of the emitter.

The system classification according to emission uniformity and its recommended ranges of design EU by ASAE Standards for different conditions are shown in Table (3).

Table (3): The system classification according to emission uniformity and its recommended ranges of design EU by ASAE Standards

\begin{tabular}{|c|c|c|c|c|c|}
\hline EU, \% & $>90$ & $\mathbf{8 0}-\mathbf{9 0}$ & $\mathbf{7 0}-\mathbf{8 0 v}$ & $\mathbf{6 6}-\mathbf{7 0}$ & $<\mathbf{6 6}$ \\
\hline $\begin{array}{c}\text { Classification } \\
\text { Merriam and Keller (1978) }\end{array}$ & Excellent & Good & Acceptable & Poor & Unacceptable \\
\hline
\end{tabular}

\section{-Statistical uniformity coefficient}

The statistical uniformity coefficient "Us" classification using statistical terms is indicated in Table (4) and defined using the following equation:

Where:

$$
\mathrm{Us}=100\left(1-\mathrm{S}_{\mathrm{d}} / \mathrm{q}_{\mathrm{a}}\right)
$$

Us $=$ the statistical uniformity of water application in \%,

$\mathrm{S}_{\mathrm{d}}=$ the standard deviation of emitter flow in $\mathrm{L} / \mathrm{h}$, and

$\mathrm{q}_{\mathrm{a}}=$ the average emitter flow measurements in $\mathrm{L} / \mathrm{h}$. 
Table (4): System classification according to ASAE (2003)

\begin{tabular}{|c|c|c|c|c|c|}
\hline Us $(\%)$ & $>90$ & $\mathbf{8 0 - 9 0}$ & $\mathbf{7 0 - 8 0}$ & $\mathbf{6 0 - 7 0}$ & $<\mathbf{6 6}$ \\
\hline Classification, & Excellent & Very good & Acceptable & Poor & Unacceptable \\
\hline
\end{tabular}

\section{-The field experiment layout}

To examine the efficiency of three types of emitter under different irrigation intervals on growth and yield of squash plants, a field experiment was designed in split plot design with three replicates. Three emitters were allocated in the main plots and the irrigation intervals were randomly distributed in the sub-plot. Each plot consisted of 50 emitter distributed on the lateral. The distance between the laterals was one meter and the distance between the emitters was 0.50 $\mathrm{m}$. The layout of the drip irrigation network was presented in Fig. (1).

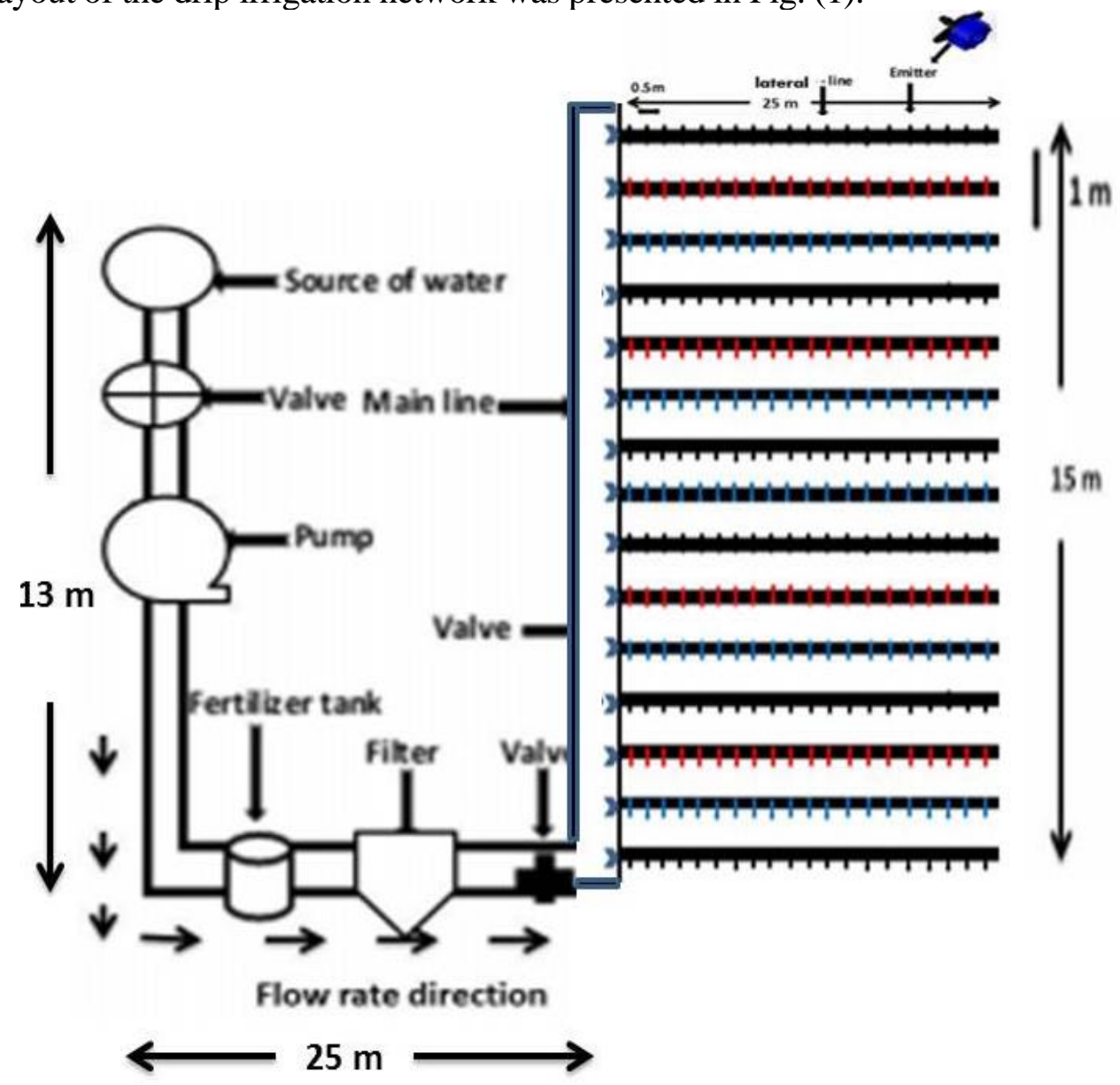

Fig. (1): Schematic diagram of a field experiment

\section{Field measurements}

At harvest, the following measurements were estimated as the average of five guarded squash plants randomly taken from each treatment. These measurements were fruit length, fruit diameter, average fresh fruit weight, percentage of water in fruit, visual appearance, average dry fruit weight, fruit dry matter, number of fruits/plants, fruit content of total sugar, total soluble solid, fruit yield/plant, and fruit content of carotene. 


\section{-Determination of fruit shape}

Fruit shape was measured by a rating system, fruit scored: very good $=9$, good $=7$, acceptable $=$ 5 , unacceptable $=3$ and poor $=1$

\section{-Total soluble solids}

The total soluble solids "TSS\%" was determined in squash fruit juice using a hand refractometer according to, AOAC, (2005).

\section{-Total sugar}

Fresh fruit samples were taken representing each treatment to determine Sucrose "\%" according to, Blakeney and Mutton, (1980).

Results were expressed as mean and the data were analyzed using Two-way ANOVA followed by least significant difference "LSD" test through SPSS 16, version 4 . The treatments means were compared using LSD at significant levels of 0.05 and 0.01, respectively as described by, Gomez and Gomez, (1984).

\section{RESULTS AND DISCUSSION}

\section{Coefficient of variation}

The coefficient of variation "C.V" showed in Fig. 2. It shows a large difference in the flow rates for the tested emitters. The flow rate of the emitter type $\mathrm{D}_{5000}$ showed the highest coefficient of variation "about 13\%" followed by $\mathrm{PC}_{\mathrm{ND}}$ emitter " about 7\%". On the other hand, the lowest desirable "C.V" was presented in the flow rate of $\mathrm{PC}_{2}$ emitter "about $5 \%$ ". In all emitters, the increase of the period between irrigations leads to increase $\mathrm{CV}$ values. The largest "C.V" was shown in $\mathrm{D}_{5000}$ emitter under the irrigation intervals every 5 days " about $15 \%$ " while the lowest one was presented in $\mathrm{PC}_{2}$ emitter under the irrigation interval day after day as indicated in Table (5).

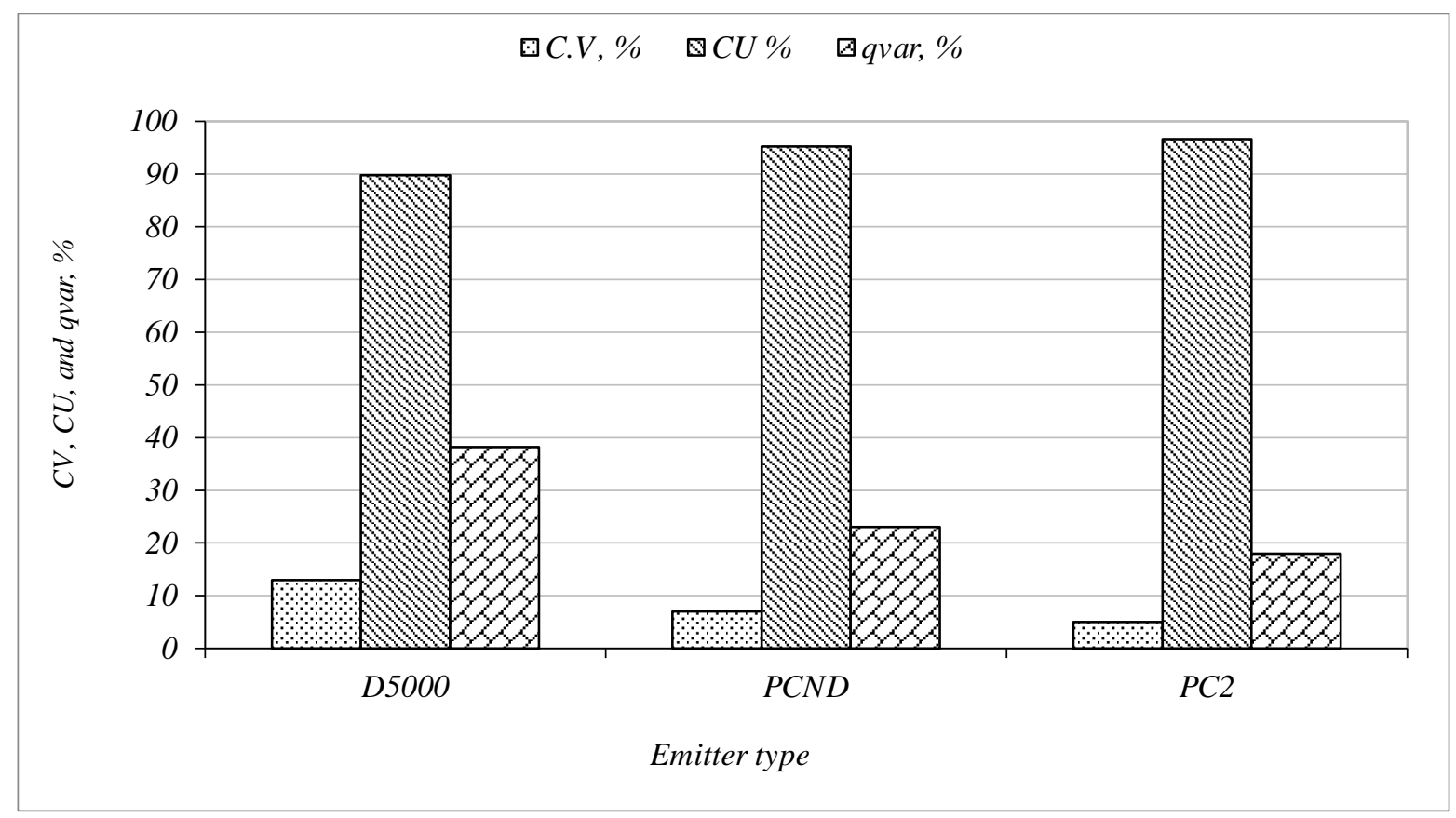

Figure (2): Emitter type effects on coefficient of variation "C.V", Christiansen's coefficient of uniformity "CU" and the flow variation "qvar." 
Table (5): The emitter performance under different irrigation intervals

\begin{tabular}{ccccccc}
\hline Emitter & Irrigation intervals & $\mathbf{C . V}, \boldsymbol{\%}$ & $\mathbf{E U}, \boldsymbol{\%}$ & $\mathbf{C U}, \boldsymbol{\%}$ & Us, \% & qvar., \% \\
\hline \multirow{3}{*}{$\mathrm{D}_{5000}$} & Day after day & 12 & 93.23 & 89.09 & 96.26 & 36 \\
\cline { 2 - 7 } & Every 3 days & 13 & 92.34 & 90.77 & 96.19 & 38 \\
\cline { 2 - 7 } & Every 5 days & 15 & 88.67 & 89.58 & 93.85 & 40 \\
\hline \multirow{3}{*}{$\mathrm{PC}_{\mathrm{ND}}$} & Day after day & 4 & 96.1 & 97.36 & 98.78 & 18 \\
\cline { 2 - 6 } & Every 3 days & 7 & 95.16 & 95.17 & 97.81 & 25 \\
\cline { 2 - 7 } & Every 5 days & 9 & 91.17 & 93.26 & 96.04 & 26 \\
\hline \multirow{3}{*}{$\mathrm{PC}_{2}$} & Day after day & 3 & 98.02 & 97.71 & 99.01 & 14 \\
\cline { 2 - 6 } & Every 3 days & 5 & 97.61 & 96.98 & 98.52 & 19 \\
\hline & Every 5 days & 7 & 97.36 & 95.28 & 96.95 & 21 \\
\hline
\end{tabular}

\section{Christiansen's uniformity coefficient}

The Christiansen's uniformity coefficient "CU" showed in Fig. 2. The results showed that all CU values of $\mathrm{PC}_{\mathrm{ND}}$ and $\mathrm{PC}_{2}$ emitters were larger than $90 \%$ while it was $<90 \%$ for $\mathrm{D}_{5000}$ emitter. $\mathrm{PC}_{2}$ emitter had the highest $\mathrm{CU}$ "about 97.71\%" followed by $\mathrm{PC}_{\mathrm{ND}}$ emitter "about 97.36\%". On the other hand, D5000 emitter had the lowest CU "about 89.09\%". Emitter CU negatively associated with irrigation intervals where the extended of irrigation interval from one day to five days resulted in a large decreased in $\mathrm{CU}$ of all tested emitters. The highest $\mathrm{CU}$ was shown in $\mathrm{PC}_{2}$ emitter under one day's irrigation interval. In the contrast $\mathrm{D}_{5000}$ emitter under irrigation interval one day had the lowest CU as presented in Table (5).

\section{Flow variation}

Fig. (2) showed that all flow variation "qvar" of $\mathrm{D}_{5000}$ and $\mathrm{PC}_{\mathrm{ND}}$ emitters were greater than $20 \%$ while the average flow variation of $\mathrm{PC}_{2}$ emitter was lower than $20 \% . \mathrm{PC}_{2}$ emitter had the lowest flow variation "about 17.36" followed by $\mathrm{PC}_{\mathrm{ND}}$ emitter "about 21.8". On the other hand $\mathrm{D}_{5000}$ emitter had the highest flow variation "about 36.9". Emitter flow variation positively associated with irrigation intervals where the extended of irrigation interval from one day to five days resulted in a large increased inflow variation of all tested emitters. The lowest flow variation was shown in $\mathrm{PC}_{2}$ emitter under one day irrigation interval. In the contrast, $\mathrm{D}_{5000}$ emitter under irrigation interval 5 days had the highest flow variation as presented in Table (5).

\section{The emission uniformity}

The emission uniformity "EU\%" presented in Table (5) confirmed that all uniformity percentage of the tested emitters were larger than $90 \% . \mathrm{PC}_{2}$ emitter had the highest $\mathrm{EU} \%$ "about $98 \% "$ followed by $\mathrm{PC}_{\mathrm{ND}}$ emitter "about $96 \% "$ ". On the other hand $\mathrm{D}_{5000}$ emitter had the lowest EU\% "about $89 \% "$. Emitter uniformity negatively associated with irrigation intervals where the extended of irrigation interval from one day to five days resulted in a large decreased in EU\% of all tested emitters. The highest EU\% was shown in $\mathrm{PC}_{2}$ emitter under one day irrigation interval. In the contrast, $\mathrm{D}_{5000}$ emitter under irrigation interval 5 days had the lowest EU\%.

\section{Statistical uniformity coefficient}

The presented data in Table (5) revealed that the statistical uniformity coefficient "Us" values for the tested emitters were $>90 \%$. $\mathrm{PC}_{2}$ emitter had the highest Us "about $99 \%$ " followed by $\mathrm{PC}_{\mathrm{ND}}$ 
emitter "about $99 \% "$. On the other hand D5000 emitter had the lowest Us "about 94\%". Emitter Us negatively associated with irrigation intervals where the extended of irrigation interval from one day to five days resulted in a large decreased in Us of all tested emitters. The highest Us was shown in $\mathrm{PC}_{2}$ emitter under one day irrigation interval. In the contrast, $\mathrm{D}_{5000}$ emitter under irrigation interval 5 day's had the lowest Us.

\section{The emitter types effects on squash fruit physical properties and yield}

The obtained data in Table (6) indicated the presence of the significant differences among all emitter types in all squash fruit physical properties (fruit length, fruit water content and fruit dry mater content) and fruit yield/plant. The results indicated that, squash yield under the type of emitter D5000 gave the highly desirable values for fruit shape "about 8.89 score", nearly 18 fruits/plant and fruit yield/plant about $1985.56 \mathrm{~g}$. While, squash yield under the type of emitter $\mathrm{PC}_{\mathrm{ND}}$ showed highly values for fruit diameter about $4.45 \mathrm{~cm}$, fresh fruit weight about $150.82 \mathrm{~g}$, dry fruit weight about $17.03 \mathrm{~g}$ and TSS about $9.66 \%$. While squash yield under the type of emitter $\mathrm{PC}_{2}$ had highly values for fruit diameter of $4.35 \mathrm{~cm}, 16$ fruit/plant, and fruit yield of $2125.11 \mathrm{~g} / \mathrm{plant}$.

Table (6): Effect of emitter types on fruit physical properties and the yield of squash plants

\begin{tabular}{|l|c|c|c|c|}
\hline \multirow{2}{*}{\multicolumn{1}{|c|}{ Mesearments }} & \multicolumn{4}{|c|}{ Emitter type } \\
\cline { 2 - 5 } & D 5000 & PCND $_{\text {N }}$ & PC $_{\mathbf{2}}$ & LSD 5\% \\
\hline Fruit length, cm & 12.97 & 14.75 & 13.87 & 2.39 (ns) \\
\hline Fruit diameter, cm & $3.97 \mathrm{~b}$ & $4.45 \mathrm{a}$ & $4.35 \mathrm{a}$ & 0.31 \\
\hline Fruit shape (score) & $8.89 \mathrm{a}$ & $7.44 \mathrm{c}$ & $8.46 \mathrm{~b}$ & 0.18 \\
\hline Fruit fresh weight, g & $120.60 \mathrm{~b}$ & $150.82 \mathrm{a}$ & $127.08 \mathrm{~b}$ & 19.47 \\
\hline Fruit dry weight, g & $12.54 \mathrm{~b}$ & $17.03 \mathrm{a}$ & $13.14 \mathrm{~b}$ & 3.36 \\
\hline Fruit water content, \% & 89.79 & 88.65 & 89.66 & $1.80(\mathrm{~ns})$ \\
\hline Dry matter, \% & 10.01 & 9.97 & 10.62 & $1.71(\mathrm{~ns})$ \\
\hline TSS, \% & $9.43 \mathrm{~b}$ & $9.66 \mathrm{a}$ & $8.99 \mathrm{c}$ & 0.11 \\
\hline No. of fruits/plant & $17.79 \mathrm{a}$ & $11.13 \mathrm{~b}$ & $16.00 \mathrm{a}$ & 3.13 \\
\hline Fruit yield/plant, g & $1985.56 \mathrm{a}$ & $1643.89 \mathrm{~b}$ & $2125.11 \mathrm{a}$ & 156.42 \\
\hline
\end{tabular}

Means followed by the same letters in a column of each experimental factors are not significantly different at $\mathrm{p}<0.05$ according to the LSD test.

\section{The effect of irrigation intervals on the fruit shape and yield}

Data presented in Fig. (5) showed the effect of irrigation intervals on the yield and the squash fruit shape under three different types of emitters. Squash plants irrigated with one day intervals had the highest fruit visual appearance 8.86 score, and fruit yield "2074 g/plant". While, plants that irrigated every three days had highly values for fruit shape "8.66" and fruit yield "1966.44g/plant". On the other hand, squash plants that irrigated every 5 days showed highly values for fruit shape and yield. The results indicated that the fruit shape and fruit yield had a polynomial relationship with the irrigation intervals under $\mathrm{D}_{5000}$ and $\mathrm{PC}_{2}$ but had a liner relation under $\mathrm{PC}_{\mathrm{ND}}$. 

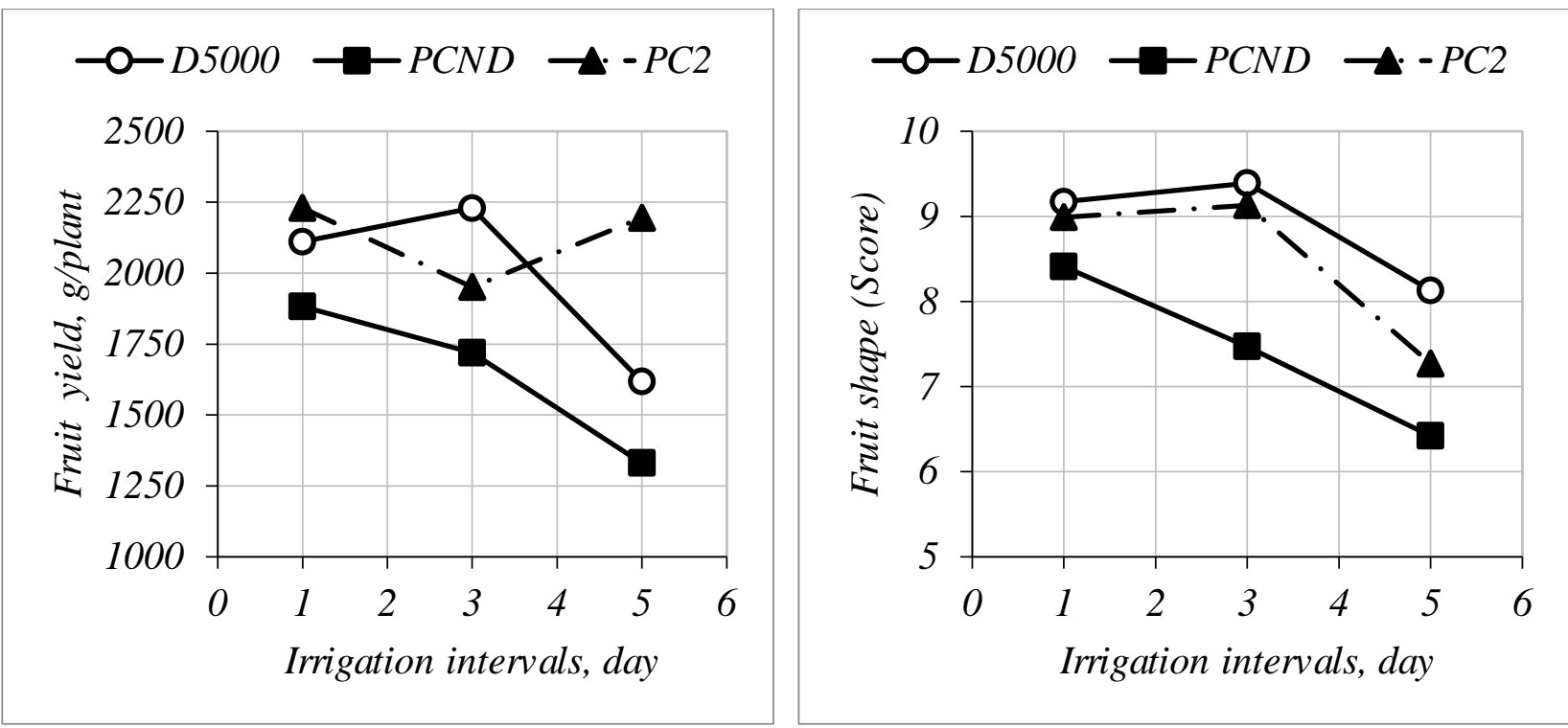

Fig. (5) : The effect of irrigation intervals on the fruit shape and yield under different emitter types

\section{Irrigation intervals and emitter types effects}

The data in Fig. (6) indicated that squash plants irrigated every three days had the highest fruit content of total sugar "about $3.70 \mathrm{mg} / \mathrm{g} \mathrm{dw}$ " followed by irrigated plants day after day. While, squash plants that irrigated every 5 days showed lowest values for fruit content of total sugar "about $1.70 \mathrm{mg} / \mathrm{g} \mathrm{dw}$ ". The obtained results also showed that, the relation between contents of squash fruit from total sugar significantly differ under the tested emitters. Squash plants irrigated by $\mathrm{D}_{5000}$ emitter gave the highest fruit content of total sugar "about $3.77 \mathrm{mg} / \mathrm{g} \mathrm{dw}$ " followed by squash plants irrigated by $\mathrm{PC}_{2}$ emitter. While, squash plants irrigated by $\mathrm{PC}_{\mathrm{ND}}$ emitter showed lowest fruit content of total sugar "about $2.22 \mathrm{mg} / \mathrm{g} \mathrm{dw}$ ". These values did not differ significant with those obtained by $\mathrm{PC}_{2}$ emitter in total sugar.

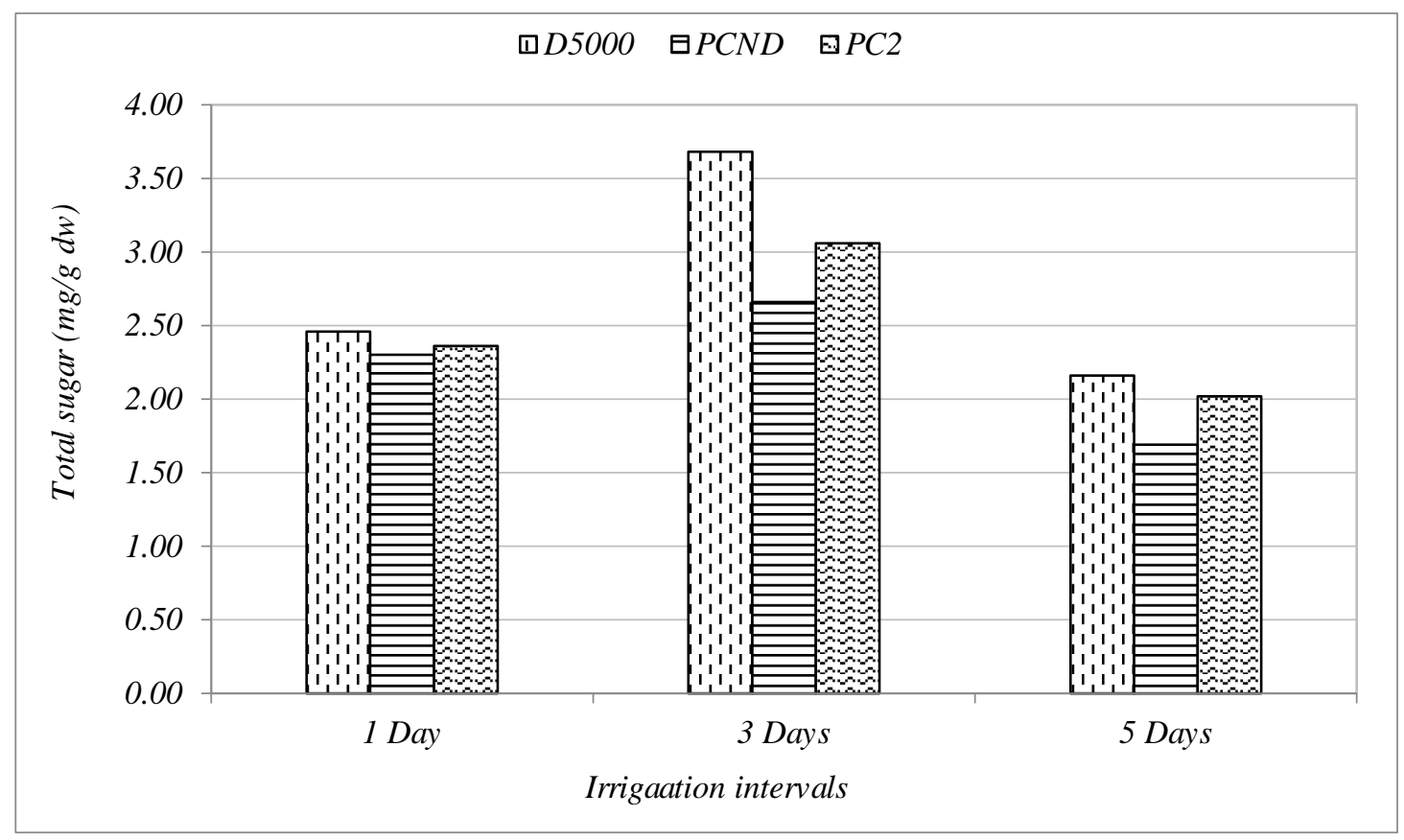

Fig. (6): The effect of irrigation intervals on total suger using different emitters 


\section{CONCLUSION}

The obtained results concluded that:

o The irrigation intervals significant effect on the flow rate of all emitters.

$\circ \quad \mathrm{PC}_{2}$ emitter can be used under irrigation day after day with lowest coefficient of variation and highest emission uniformity.

- Squash plants under $\mathrm{PC}_{2}$ emitter gave the highest fruit yield and fruit quality.

- Irrigated squash plants every three days resulted in high significant increase in fruit yield and fruit quality.

- Irrigated squash plants every three days using $\mathrm{PC}_{2}$ was recommended under the Nile Delta conditions.

\section{REFERENCES}

Abdelsalam, H.S. (2016). Effect of Some Engineering Factors On Pressurized Irrigation Performance. M.Sc. Benha Univ., Benha, Egypt, pp. 13-16.

Al-Mefleh, N. K.; Bashabsheh, I.; Talozi S. and Al-Issa T. A. (2015). Field evaluation of the performance of different irrigation emitter types using treated wastewater. Water Quality Research Journal of Canada, 50(3):240-251.

ASAE (American Society of Agricultural Engineers) (1998). Field evaluation of microirrigation systems. ASAE STANDARDS EP458 DEC97: 908 - 914.

ASAE (American Society of Agricultural Engineers) (2003). Design and installation of micro irrigation systems. EP 405.1 FEB03. St Joseph, Michigan, ASAE. 901- 905.

ASAE. (American Society of Agricultural and Biological Engineers Standards EP369.1) (2014); Design of Agricultural Drainage Pumping Plants ASABE: St. Joseph, MI, USA.

AOAC. (2005). Official methods of analysis of the Association of Official Analytical Chemists (18th ed.), Gaithersburg, MD, USA.

Blakeney, A. B. and Mutton, L. L. (1980). A simple colorimetric method for the determination of sugars in fruit and vegetables. Journal of the Science of Food and Agriculture, 31(9), 889897.

Elamin, A. W. M.; A. M. A. Eldaiam; N. A. Abdalla; and M. E. Hussain (2017). Hydraulic performance of drip irrigation system under different emitter types, and operating pressures using treated wastewater at Khartoum state. International J. Develo. and Sustainability, 6(9):1086-1095.

Gomez, K.A. and A. A. Gomez (1984). Statistical procedurces for agricultural research. John Willey \& Sons (ed.), New York NRX6-G2N-S6H4. USA.

Hanson, B. R.; D. E. May; J. Simnek; J. W. Hopmans; and R.B. Hutmacher (2009). Drip irrigation provides salinity control needed for profitable irrigation of toma-toes in the San Joaquin Valley. Calif., Agr., 63:131-136. 
Locascio, S. J. (2005). Management of irrigation for vegetables: Past, present, and future. Hort. Technology, 15:482-485.

Lui, H. J. and G. H. Huang (2009). Laboratory experiment on drip emitter clogging with fresh water and treated sewage effluent. Agri. Water Manage., 96:745-756.

National Research Council (2010). Toward sustainable agricultural systems in the 21 st century. National Academy Press, Washington, DC., USA.

Phocaides, A .(2000). Technical Hand Book on Pressurized Irrigation Techniques. FAO Consult., Rome, Italy, 195p.

Ravina, I.; E. Pas; Z. Sofer; A. Marcu; A. Schischa; G. Sagi; Z. Yechialy and Y. Lev (1997). Control of clogging in drip irrigation with stored treated municipal sewage effluent. Agri. Water Manage., 33:127-137.

Ribeiro, P. A. A. and R. D. Coelho (2010). Teixeira, M. B. Clogging of conventional drip tubes with application of potassium chloride (white and red) via two water qualities. Agricultural Engineering, 30:279-287.

Sarker, K. K.; A. Hossain; K. F. I. Murad; S. K. Biswas; F. Akter; R. P. Rannu; M. Moniruzzaman; N. N. Karim and J. Timsina (2019). Development and Evaluation of an Emitter with a Low-Pressure Drip-Irrigation System for Sustainable Eggplant Production. Agri. Engineering, 1:376-390.

Sinobas, L. R. and M.G. Rodríguez (2012). A Review of Subsurface Drip Irrigation and Its Management, Water Quality, Soil and Managing Irrigation of Crops, Dr. TeangShui Lee (ed.), ISBN, 938-953-51-0426-1. 
تأثير أنواع النقاطات وفترات الري المختلفة على إنتاجية وجودة الكوسة تحت ظروف دلتا النيل

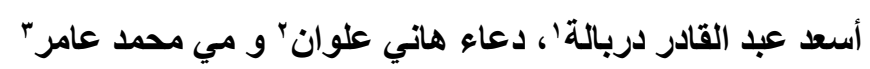

' أستاذ الهنسة الزراعية ـ قسم الهنسة الزراعية ـ كلية الزر اعة - جامعة طنطا - مصر.

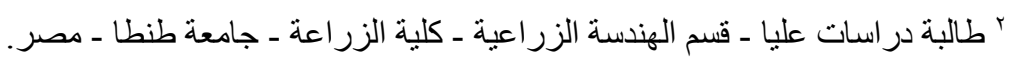

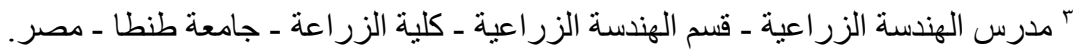

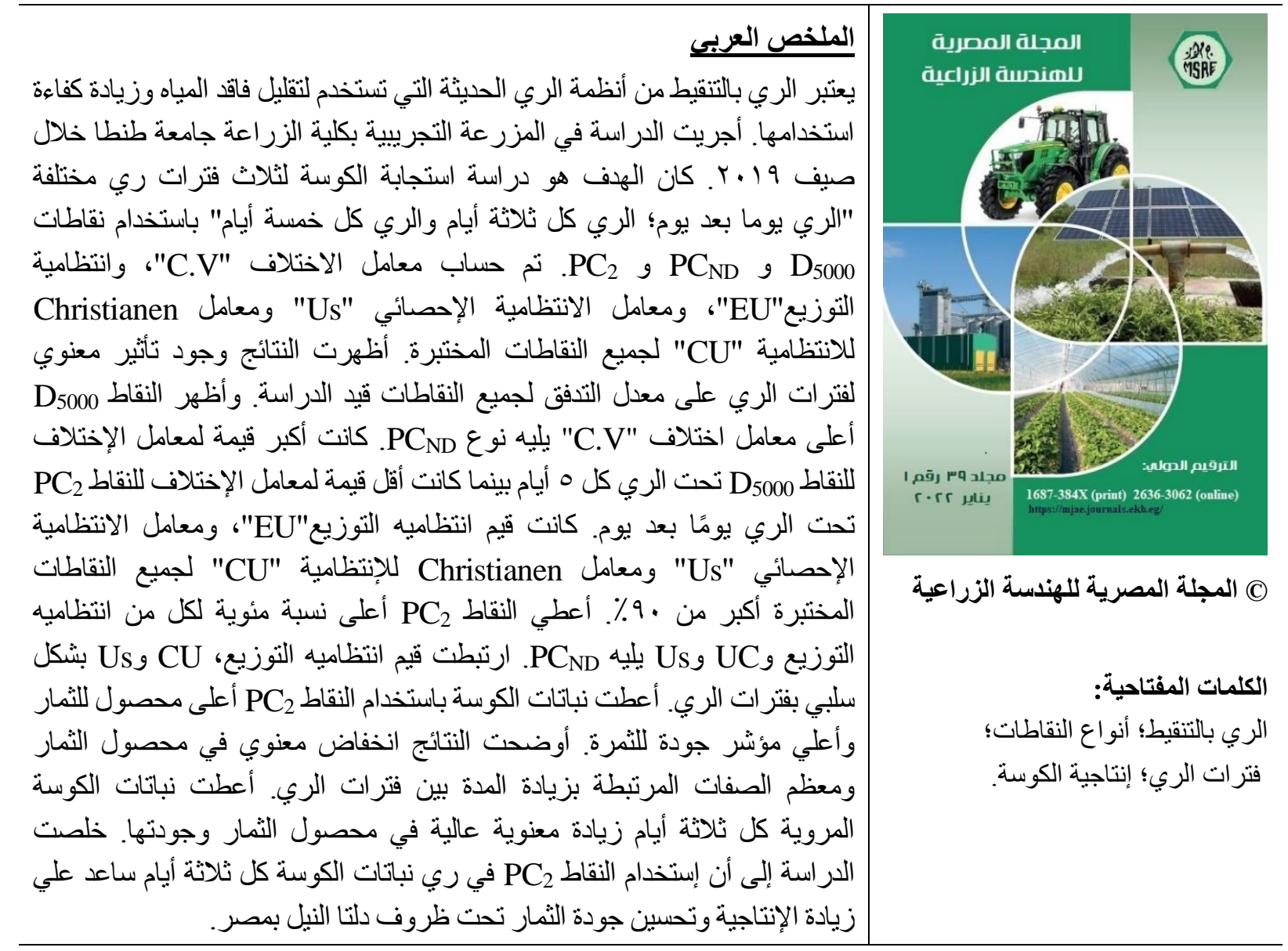

